\title{
Pathogenicity and proteome production of Isaria fumosorosea (=Paecilomyces Fumosoroseus) (WISE) isolates against lemon butterfly, Papilio demoleus (Papilionidae: lepidoptera)
}

\author{
Vinayaga Moorthi ${ }^{1 *}$, P. C. Balasubramanian ${ }^{2}$, Pasco B. Avery ${ }^{3}$, Selvarani, S. ${ }^{2}$, T. Kubendran ${ }^{1}$, \\ T. Rathinakumar and A. Najitha Banu ${ }^{1}$ \\ ${ }^{1}$ Department of Zoology, Thiagarajar College, Madurai-625009, India. \\ ${ }^{2}$ Department of Zoology, Thiagarajar College, Madurai-625009, India. \\ ${ }^{3}$ University of Florida, Institute of Food and Agricultural Sciences, Indian River Research and Education Centre. 2199 \\ South Rock Road, Fort Pierce, FL34945, USA.
}

Received 11 February, 2012; Accepted 1 June, 2012

\begin{abstract}
The pathogenic potential and catalytic triad conserved amino acids of the isolates Isaria fumosorosea (=Paecilomyces fumosoroseus) (Ifr ${ }_{1}$ and $I f r_{2}$ ) in response to Papilio demoleus was analysed. The isolates showed its potential in killing $P$. demoleus causing mortality of 72.23 and $61.90 \%$ at the end of 8 days with $10^{8}$ spores $\mathrm{ml}^{-1}$ concentrations. The enzyme assays (higher proteolytic and chitinolytic activity) also showed that the Ifr ${ }_{2}$ was more efficient than $I f r_{1}$. The predictions of catalytic triads (serine, histidine and asparagine) were also visualized in the peak level obtained in infra-red (IR) and $\mathrm{H}_{1}$ nuclear magnetic resonance (NMR) spectra. With this information it was suggested that, partial characterization of catalytic domain was predicted in the fungal isolates Ifr.
\end{abstract}

Key words: Entomopathogenic fungi, Isaria fumosorosea, Papilio demoleus, biological control.

\section{INTRODUCTION}

The insect pest management programs heavily rely on the use of synthetic chemical based insecticides or pesticides and herbicides, which is a multibillion dollar industry. The main driving force behind chemical insecticides is the fast speed of kill, high efficacy and political influence of the companies involved in this business. Microbial control is another approach for biological means of plant protection. The use of pathogens in biological control can be integrated with other natural enemies and the immediate effect of a microbial control agent can protect the crops, when parasitoids and predators are unable to maintain the pest population below the economic threshold level.

Fungi are particularly important for controlling sap

${ }^{*}$ Corresponding author. E-mail: vinayputhu@gmail.com.

Author(s) agree that this article remains permanently open access under the terms of the Creative Commons Attribution License 4.0 International License 
sucking insects (white flies) for which there is no alternative available in the present biocontrol agents. Among them, Isaria fumosorosea (=Paecilomyces fumosoroseus) strains occur in soils and insects world-wide. Their efficacy against Bemisia argentifolii and Trialeurodes vaporariorum has been described by Wraight et al. (1998) and Fang et al. (1985). Nevertheless, different strains of the same species do not have equal potentials for the control of the same arthropod species (Altre et al., 1999; Vey et al., 1982).

Pathogenicity of an antagonist towards an insect species is related to the ability of the fungus to germinate on the insects' cuticle and to penetrate it, to its production of secondary metabolites and to the defense mechanisms of the host to prevent fungal infection and growth (Kaijiang and Roberts, 1986; Rath et al., 1996; Clarkson et al., 1998; St. Leger et al., 1989). The synthesis of extracellular enzymes is crucial for the infection process of this fungus. Successful infection primarily relies on the synthesis of molecular scissors such as extracellular proteases, chitinases and esterases (Clarkson and Charnley, 1996). The insect infection relies on protease(s) action because $75 \%$ of the cuticle is made up of proteins. Furthermore, chitinase(s) help degradation of $\mathrm{N}$-acetyl-D-glucosamine moieties present in the cuticle (Charnley, 1997).

Due to the significance of proteases in breaching the insect cuticle, they have received more attention from researcher's worldwide. During more than three decades of research on Entomo-Pathogenic Fungi (EPF), several investigators have established two proteases, namely subtilisins and trypsins, as important virulence factors (St. Leger et al., 1986, 1988). Although the overall fold of various serine proteases may differ, they all follow the same mechanism of action through an identical stereochemistry of the catalytic triad and oxyanion hole. In this mechanism, the serine functions as the primary nucleophile and the histidine plays a dual role as the proton donor and acceptor at different steps in the reaction. The role of asparagine is believed to bring the histidine into the correct orientation to facilitate the nucleophilic attack by the serine. The role of the oxyanion hole is to stabilize the developing negative charge on the oxygen atom of the substrate during the formation of the tetrahedral intermediate (Russell and Fersht, 1987; Dodson and Wlodawer, 1998; Birktoft and Blow, 1972).

In order to increase their utilization, research needs to concentrate on: (a) pathogen virulence and speed of kill, (b) pathogen performance under challenging environmental conditions (cool weather, dry conditions etc.), (c) efficiency in the production process, (d) formulations that enable ease of application, increased environmental persistence and longer shelf-life, (e) integration into managed ecosystems and interaction with the environment and other integrated pest management (IPM) components (Lacey et al., 2001). The three proteases PR1 (Metarhizium anisopliae), VCP1 (Verticillium chladosporium) and Ver112
(Verticillium licanii) have shown that they have a high degree of sequence similarity with each other and belong to the proteinase $\mathrm{K}$ family of subtilisin-like serine proteases (subtilases) which is a large family of endopeptidases found only in fungi and Gram-negative bacteria (Siezen and Leunissen, 1997). These enzymes show conservation of the Asp- His-Ser catalytic triad and catalytic domain.

However, the three-dimensional (3D) structures have not been resolved for any of the cuticle-degrading proteases so far by either X-ray crystallography or nuclear magnetic resonance (NMR) techniques. The lacuna of cuticle degrading protease, in the present study reveals that the enzymatic catalytic domain is analyzed through IR and NMR, which provide concrete idea of a particular domain involved in cuticle degradation.

\section{MATERIALS AND METHODS}

\section{Preparation of the test insects and bioassay}

The test lepidopteran insect Papilio demoleus (L.) (Papilionidae: Lepidoptera) was maintained on citrus fresh leaves at $27 \pm 2 \square \mathrm{C}, 70 \pm$ $5 \%$ relative humidity $(\mathrm{RH})$ and $14 \mathrm{~h}$ photoperiod under laboratory conditions. Citrus leaves were washed with diluted potassium permanganate solution $(0.001 \%)$ followed by distilled water to prevent microbial contamination.

Leaves were kept in shade at room temperature until the distilled water evaporates. All the glassware used in the experiments were washed thoroughly in detergent, treated with $2 \%$ formalin and then dried in an oven at $70 \square \mathrm{C}$ for $4 \mathrm{~h}$ to check microbial contaminations. The $2^{\text {nd }}$ instar larvae of $P$. demoleus was collected from citrus field near Madurai, Tamil Nadu, India and brought into the laboratory, reared in a wooden cage $(60 \times 60 \mathrm{~cm})$ providing adequate citrus leaves as a stock culture. The $3^{\text {rd }}$ instar larvae were from stock in this study.

\section{Isolation protocol of $I$. fumosorosea}

Isolation protocol of Ifr isolates followed the method of Haraprasad et al. (2001). Ifr was isolated from the soil in different locations of Madurai and Theni district, Tamil Nadu. One gram of soil was diluted with $100 \mathrm{ml}$ of distilled water and was serially diluted. From each dilution, $100 \mu \mathrm{l}$ was placed on PDA medium and it was fortified with streptomycin $(10 \mathrm{mg} / 100 \mathrm{ml})$. It was allowed to grow for 7 days at $27 \pm 2^{\circ} \mathrm{C}$ (Haraprasad et al., 2001) in the respective media. After 7 days of incubation the fungal colony was identified. The identified fungal colony was sub-cultured in Saboraud Dextrose Agar (SDA) (Hi-Media). The sterilized medium was transferred into sterile Petri dishes (Borosil ${ }^{\circledR}$ ) and test tubes $\left(\right.$ Borosil $^{\circledR}$ ) that were then inoculated with conidia by streaking. The isolated fungus Ifr was used for the pathogenicity and enzyme studies against $P$. demoleus.

\section{Efficiency of $I$. fumosorosea towards $P$. demoleus}

The isolates of $I$. fumosorosea were used to determine the pathogenicity of $P$. demoleus. Pure culture of the test fungal species, I. fumosorosea isolates was grown on SDA at $27 \pm 2^{\circ} \mathrm{C}$ until a dense sporulating mat was produced (14 days). The conidial suspension of $10^{8}$ conidia per milliliter was prepared by counting the 
Table 1. Cumulative mortality (\%) of the third instar larvae of Papilio demoleus inoculated with various conidia concentrations of the $I r f_{1}$ isolate of Isaria fumosorosea .

\begin{tabular}{|c|c|c|c|c|}
\hline \multirow{2}{*}{$\begin{array}{c}\text { Conidial } \\
\text { concentration } \\
\left(\text { conidia } \mathrm{ml}^{-1}\right)\end{array}$} & \multicolumn{4}{|c|}{ Period (days) after treatment } \\
\hline & 2 & 4 & 6 & 8 \\
\hline $1 \times 10^{5}$ & $\begin{array}{c}0.00 \\
(1.16)^{\mathrm{cd}}\end{array}$ & $\begin{array}{c}5.56 \\
(13.63)^{d}\end{array}$ & $\begin{array}{c}5.56 \\
(13.63)^{d}\end{array}$ & $\begin{array}{c}11.11 \\
(19.47)^{d}\end{array}$ \\
\hline $1 \times 10^{6}$ & $\begin{array}{c}5.56 \\
\left(13.63^{\text {bd }}\right.\end{array}$ & $\begin{array}{c}5.56 \\
(13.63)^{\mathrm{cd}}\end{array}$ & $\begin{array}{c}11.11 \\
(19.47)^{\mathrm{cd}}\end{array}$ & $\begin{array}{c}11.11 \\
(19.47)^{\mathrm{cd}}\end{array}$ \\
\hline $1 \times 10^{7}$ & $\begin{array}{c}5.56 \\
(13.63)^{b d}\end{array}$ & $\begin{array}{c}33.33 \\
(35.26)^{b}\end{array}$ & $\begin{array}{c}50.50 \\
(45.00)^{b}\end{array}$ & $\begin{array}{c}55.56 \\
(48.19)^{b}\end{array}$ \\
\hline $1 \times 10^{8}$ & $\begin{array}{c}27.78 \\
(31.80)^{a}\end{array}$ & $\begin{array}{c}38.89 \\
(38.58)^{a}\end{array}$ & $\begin{array}{c}55.36 \\
(48.19)^{\mathrm{a}}\end{array}$ & $\begin{array}{c}72.23 \\
(58.20)^{a}\end{array}$ \\
\hline Control & $\begin{array}{c}0.00 \\
(2.86)^{\mathrm{c}}\end{array}$ & $\begin{array}{c}0.33 \\
(3.29)^{\mathrm{c}}\end{array}$ & $\begin{array}{c}0.67 \\
(4.69)^{\mathrm{e}}\end{array}$ & $\begin{array}{c}4.67 \\
(12.48)^{d}\end{array}$ \\
\hline
\end{tabular}

Each value is mean of three replicates. Values in parenthesis are arc sine transformed values; $a$ - $d$ represents the levels of treatments: ' $a$ ' = best treatment and ' $d$ '= pooor treatment.

spores in improved Neubauer counting chamber (Superior Marienfeld, Germany). The conidial suspension per milliliter $\left(10^{5}\right.$ $10^{8}$ conidia per $\mathrm{ml}$ ) was prepared for the experimental studies.

Bioassays with different Ifr fungal isolates were carried out by dipping 15 third instar larvae of $P$. demoleus in conidial suspensions plus $0.02 \%$ Tween 20 at each concentration for $30 \mathrm{~s}$. After 30 $\mathrm{s}$, the larvae was transferred to sterile filter paper and then placed in individual sterilized containers having single citrus leaf previously surface sterilized and was cleaned with sterilized paper towels to eliminate excess water. The bioassay setup was conducted in room at $27 \pm 2{ }^{\circ} \mathrm{C}$ at $70 \pm 5 \% \mathrm{RH}$. Each bioassay per concentration was performed in triplicates. A group of larvae (10 in each replicate) was maintained as control treatment; only distilled water plus $0.02 \%$ Tween 20. The larvae of $P$. demoleus were observed 2, 4, 6 and 8 days after inoculation with each conidial suspension. The dead larvae were placed in a controlled growth chamber to stimulate the development of fungal mycelia and confirm that the death was by infection of the Ifr isolates.

\section{Fungal hydrolytic enzymes quantification and separation}

The fungal hydrolytic enzyme activities such as $\alpha$-amylase, proteolytic and chitinolytic activites were determined using Bernfeld (1956), St. Leger et al. (1987) and Ulhoa and Peberdy (1992) methods accordingly.

\section{Prediction of catalytic triad of cuticle degrading protease}

Ammonium sulphate precipitated culture supernatants were centrifuged at $5000 \mathrm{rpm}$ for $10 \mathrm{~min}$ using refrigerated centrifuge. The precipitate was dissolved in the solvent (Butanol: Glacial acetic acid: Water in the ratio of $4: 1: 5)$ and then amino acid separations was carried out using Thin Layer Chromatography (TLC). The collected colored fractions were then used for the analysis in the Fourier Transform Infra-Red (FTIR, NEXUS-672 model) and the spectrum was taken in the mid Infra-Red (IR) region of 400-4000 $\mathrm{cm}^{1}$. Nuclear Magnetic Resonance (NMR, Bruker $(300 \mathrm{MHz})$ spectroscopy was also used to to predict the catalytic triad amino acids (asparagine, histidine and serine) of cuticle degrading protease of $I$. fumosorosea secretome. The samples were dissolved by using deuterated chloroform $\left(\mathrm{CDCL}_{3}\right)$ as solvent.

\section{Statistical analysis}

Analysis of variance and Duncan's multiple range test (DMRT) was performed to determine the best treatment using SPSS 10 and AGRESS softwares.

\section{RESULTS}

\section{The efficacy of $I$. fumosorosea on P. demoleus}

The present study reveals the efficiency of $I$. fumosorosea isolates against $P$. demoleus at various spore concentration of $10^{5}$ to $10^{8}$ at different days $\left(2^{\text {nd }}\right.$, $4^{\text {th }}, 6^{\text {th }}$ and $8^{\text {th }}$ days) of post treatment (Tables 1 and 2 ). It was observed that, $72.23 \%$ (75\%) mortality was found in Ifr $_{1}$ (Azhagar kovil) isolate on 8 days at $10^{8} \mathrm{spore} / \mathrm{ml}$ whereas only $61.90 \%$ mortality was verified by Ifr $_{2}$ isolate. The control treatment unveiled the least mortality of $P$. demoleus by the tested isolates. The mortality due to $\mathrm{Ifr}_{2}$ isolate at the initial spore concentration $\left(10^{5}\right)$ was at the average of $4.76 \%$ only. The mean mortality of the Ifr $_{2}$ isolate ranged from 3.57 to $36.90 \%$. Furthermore, by the 6 days at $10^{8}$ concentrations only the $/$ fr $_{1}$ isolate promoted $50 \%$ mortality towards $P$. demoleus.

Enzymatic role of $I$. fumosorosea in the pathogenesis of $P$. demoleus was analysed quantitatively by different hydrolytic enzyme assays such as a-amylase activity, proteolytic activity and chitinolytic activity and are represented in Figures 1 and 2. Supernatant obtained from minimal medium in the presence and absence of $P$. demoleus exoskeleton were double filtered after 3 days of incubation and comparatively higher protein secretion was found in the Minimal Medium + Cuticle (MMC) by the $I f r_{1}$ than $\mathrm{MM}$ and $I \mathrm{fr}_{2}$. This may also have helped the $I f r_{1}$ isolate to contribute higher percent mortality than $\mathrm{Ifr}_{2}$.

\section{Structural elucidation of catalytic triad}

Prediction of catalytic triad conserved amino acids of cuticle degrading protease such as serine, histidine and asparagine in the fungal secretome was carried out using FTIR and ${ }^{1} \mathrm{H}$ NMR with their basic structures (Figures 3 and 4).

\section{DISCUSSION}

Naturally occurring entomopathogens play an important role in our ecosystem. Invertebrates, viruses, bacteria and fungi can be found as regulatory factors in insect populations. Hence, many species are used as biological control agents of insect pests in row and glasshouse crops, orchards, turf, stored products and forestry and for abatement of vector insects of veterinary and medical 
Table 2. Cumulative mortality (\%) of the third instar larvae of Papilio demoleus inoculated with various conidia concentrations of the $\mathrm{Irf}_{2}$ isolate of Isaria fumosorosea

\begin{tabular}{|c|c|c|c|c|}
\hline \multirow{2}{*}{$\begin{array}{l}\text { Conidial concentration } \\
\left(\text { conidia } \mathrm{ml}^{-1}\right)\end{array}$} & \multicolumn{4}{|c|}{ Period (days) after treatment } \\
\hline & 2 & 4 & 6 & 8 \\
\hline $1 \times 10^{5}$ & $\begin{array}{c}0.00 \\
(1.08)^{\mathrm{c}}\end{array}$ & $\begin{array}{c}4.76 \\
(12.60)^{\mathrm{d}}\end{array}$ & $\begin{array}{c}4.76 \\
(12.60)^{\mathrm{d}}\end{array}$ & $\begin{array}{c}4.76 \\
(12.60)^{\mathrm{d}}\end{array}$ \\
\hline $1 \times 10^{6}$ & $\begin{array}{c}4.76 \\
(12.60)^{\mathrm{bd}}\end{array}$ & $\begin{array}{c}14.26 \\
(22.20)^{\mathrm{c}}\end{array}$ & $\begin{array}{c}19.04 \\
(25.87)^{c}\end{array}$ & $\begin{array}{c}23.80 \\
(29.20)^{\mathrm{c}}\end{array}$ \\
\hline $1 \times 10^{7}$ & $\begin{array}{c}4.76 \\
(12.60)^{\mathrm{bd}}\end{array}$ & $\begin{array}{c}19.04 \\
(25.87)^{\mathrm{bc}}\end{array}$ & $\begin{array}{c}23.80 \\
(29.20)^{\mathrm{bc}}\end{array}$ & $\begin{array}{c}48.61 \\
(43.63)^{b}\end{array}$ \\
\hline $1 \times 10^{8}$ & $\begin{array}{c}19.04 \\
(25.87)^{\mathrm{a}}\end{array}$ & $\begin{array}{c}28.57 \\
(32.31)^{a}\end{array}$ & $\begin{array}{c}38.09 \\
(38.11)^{\mathrm{a}}\end{array}$ & $\begin{array}{l}61.90 \\
(51.88)^{\mathrm{a}}\end{array}$ \\
\hline Control & $\begin{array}{c}0.00 \\
(2.86)^{\mathrm{C}}\end{array}$ & $\begin{array}{c}0.00 \\
(2.86)^{c}\end{array}$ & $\begin{array}{c}0.67 \\
(4.69)^{\mathrm{c}}\end{array}$ & $\begin{array}{c}3.00 \\
(9.97)^{\mathrm{C}}\end{array}$ \\
\hline
\end{tabular}

Each value is mean of three replicates; Values in parenthesis are arc sine transformed values; a - $d$ represents the levels of treatments. That is ' $a$ ' = best treatment and ' $d$ '= poor treatment.

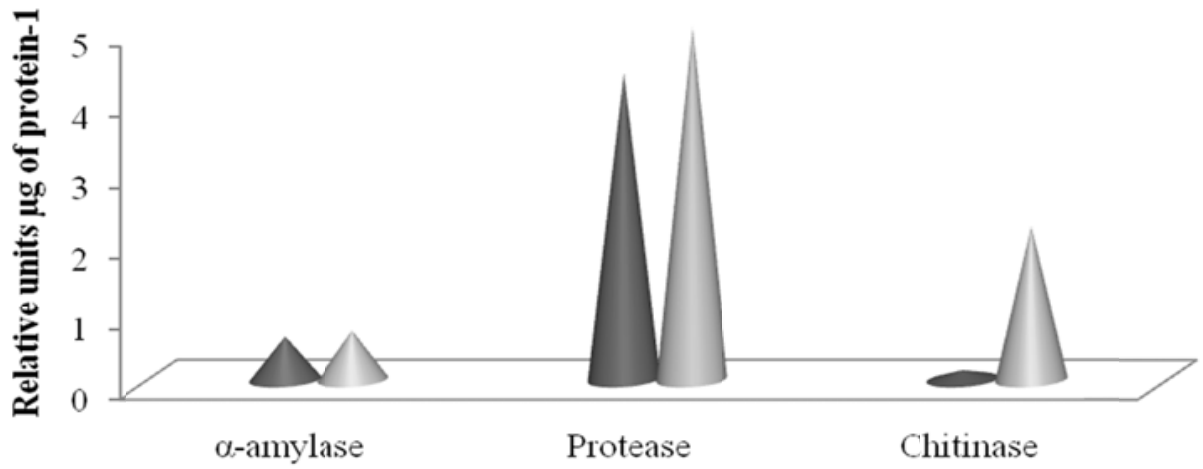

Enzyme assay

$\because \mathrm{MM}=\mathrm{MMC}$

Figure 1. Secretome production of Ifr ${ }_{1}$ isolate of Isaria fumosorosea response to Papilio demoleus exoskeleton.

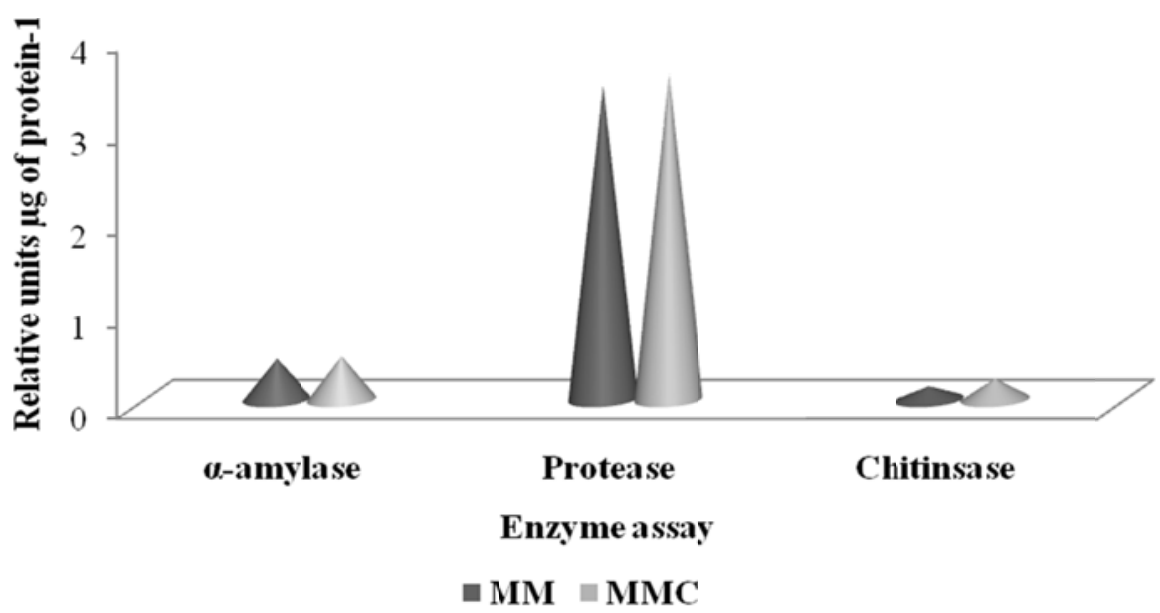

Figure 2. Secretome production of Ifr $_{2}$ isolate of Isaria fumosorosea response to Papilio demoleus exoskeleton. 


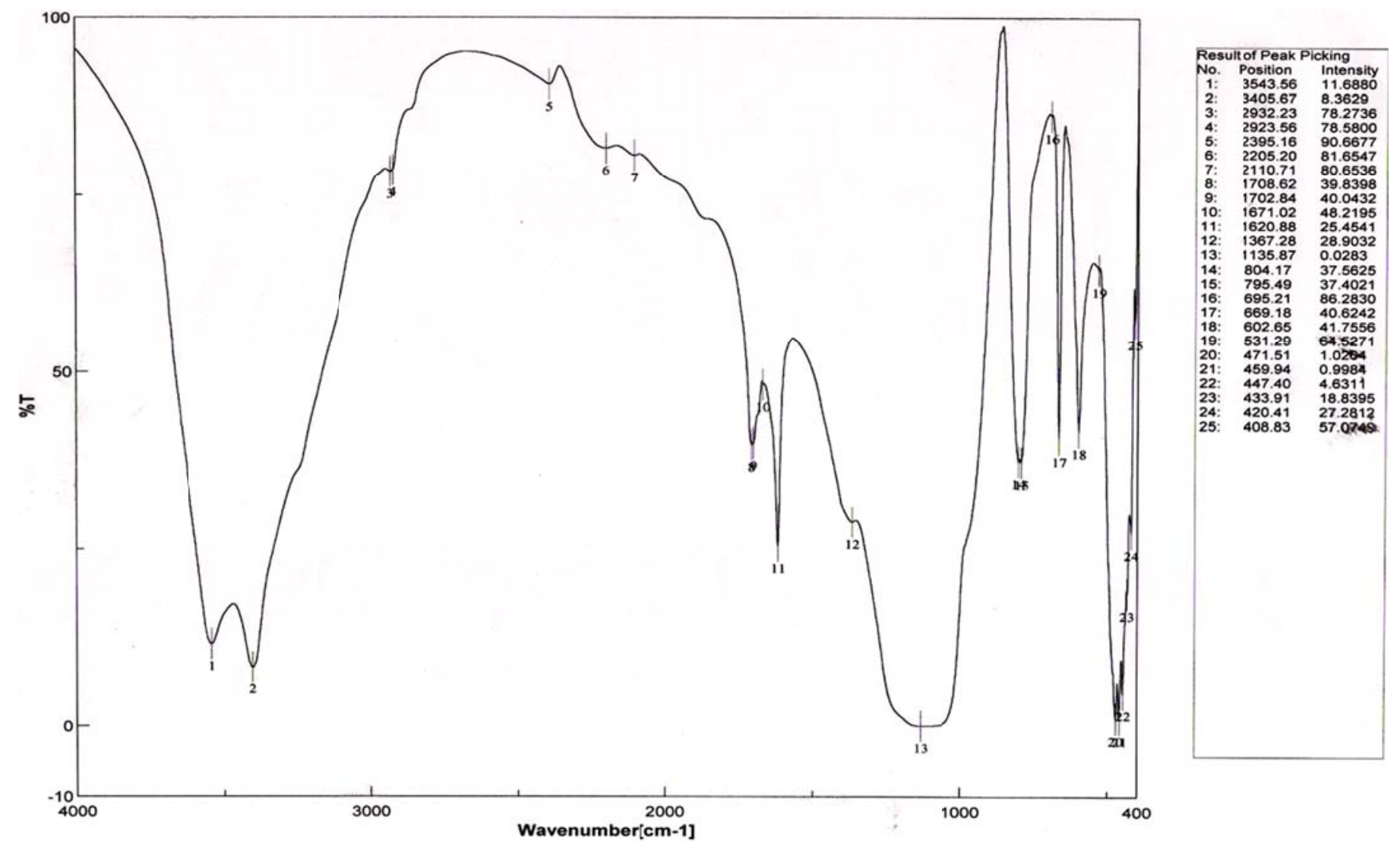

Figure 3. Fourier transform infra-red (FTIR) analysis of catalytic triad conserved amino acid of cuticle degrading proteases of Isaria fumosorosae.

importance. However, while fungal insecticides have been employed widely in China and to a lesser extent in Eastern Europe as well as in parts of South America, fungi have been little used elsewhere (Charnley, 1997). The virulence of the isolates towards $P$. demoleus was determined to identify the most promising candidate.

In the present study, the tested isolates differed in their pathogenicity towards $P$. demoleus that is the highest mortality caused by the ${ } \mathrm{fr}_{1}$ and $\mathrm{Ifr}_{2}$ isolates was 72.23 and $61.90 \%$ respectively. The results of present investigations are in accordance with the findings of Nugroho and Ibrahim (2004).

The faster infectivity or shorter time to the broad mite mortality was caused by $P$. fumosoroseus with 2.783 days and gave $50 \%$ mortality while Beauveria bassiana took 3.349 days and $M$. anisopliae took 4.280 days to cause $50 \%$ mortality (Nugroho and Ibrahim, 2004). The reason behind the difference in mortality may be due to the larval susceptibility.

The insect cuticle acts as a barrier for fungal penetration and its thickness increases with every molting so that differences in the susceptibility of different larval instars to entomopathogenic fungi can be explained by their cuticle properties (Boucias and Pendland, 1991). Malsam (1999) reported no differences in the suscep- tibility of different larval stages to entomopathogens; an increased adult mortality and a decrease in the reproduction caused by $M$. anisopliae. Van De Veire et al. (1996) observed similar susceptibility to $P$. fumosoroseus in all larval stages and adults except for the 2nd stage, which was less susceptible.

The length of the inter-molt period depends upon the environmental conditions and the shorter it gets the less time remains for the fungus to germinate and penetrate. If molting occurs shortly after inoculation the entreating fungus may be removed prior to the colonisation of the insect (Vey and Fargues, 1977; Fargues and RodriguezRueda, 1971).

Hence, the differences in the mortality can be explained by the time of inoculation regarding the remaining period to ecdysis. Presumably, susceptibility of most insects to entomopathogens is related to spore dosage. The speed of kill is influenced by the number of infection propagules in contact with the cuticle.

For most insect/ pathogen combinations a positive correlation between the number of infective spores and mortality by mycosis has been established (Liu et al., 1989; Vestergaard et al. 1995). Additionally, not all areas of the insect cuticle are equally vulnerable to penetration by propagules of entomopathogenic fungi (Butt and Goettel, 


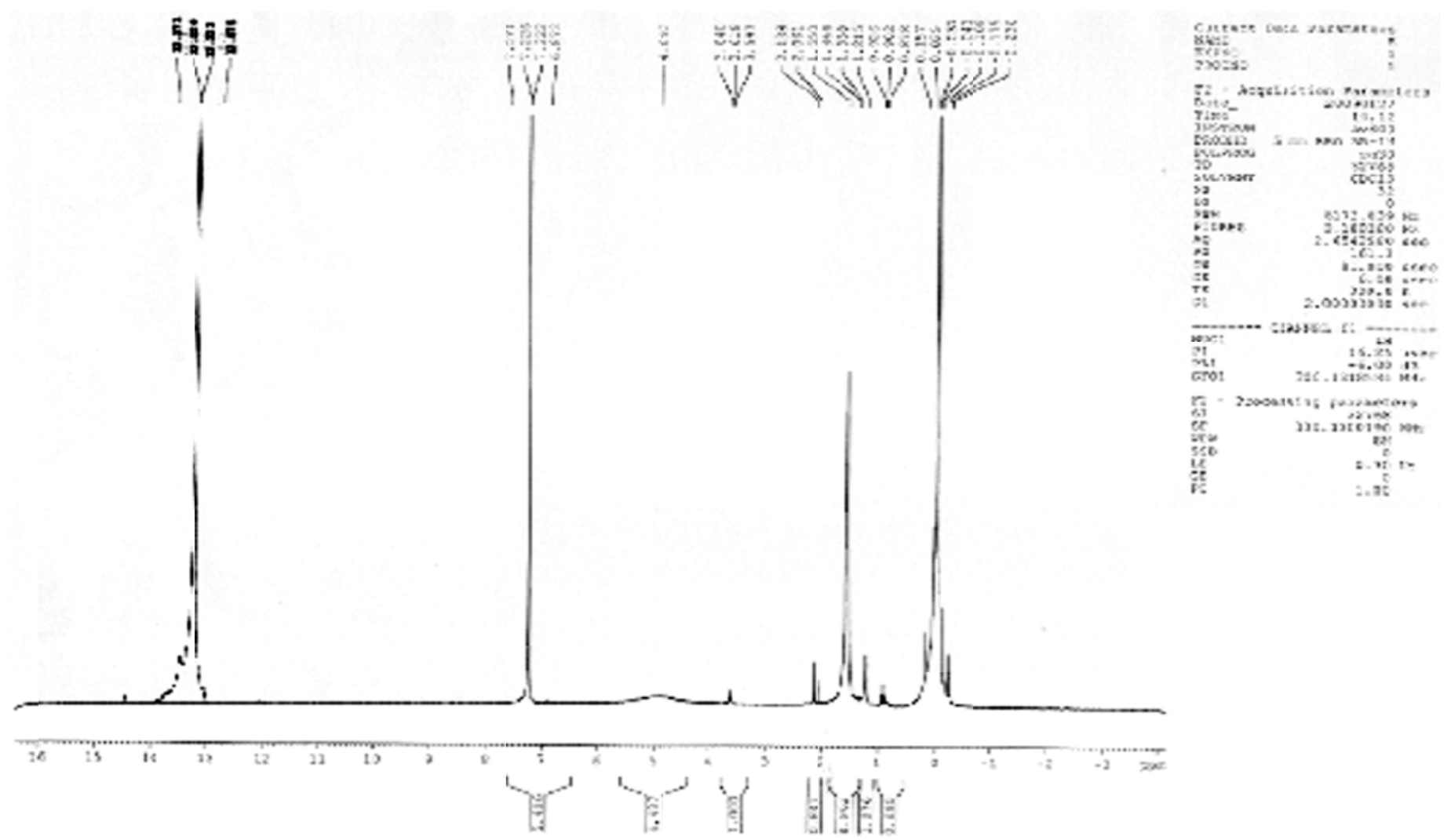

Figure 4. ${ }^{1} \mathrm{H}$ nuclear magnetic resonance (NMR) analysis of catalytic triad conserved amino acid of cuticle degrading proteases of Isaria fumosorosea.

2000). The preferential sites of invasion by fungi are often the buccal cavity, the area under the elytra, the intersegmental folds or spiracles, where locally high humidity promotes germination and the cuticle is nonsclerotised and more easily penetrated (Charnley, 1989; Clarkson and Charnley, 1996; Hajek and St. Leger, 1994; Schabel, 1976). In the present study, it was evident that, spore concentration at $10^{8}$ revealed higher mortality to $P$. demoleus and particularly, Ifr ${ }_{1}$ isolate hed the higher control potential among the isolates and the spore concentration considered and reccommended for the effective mangement of $P$. demoleus.

The present investigation found relatively slight increase in the secretion of protease by the $/ \mathrm{fr}_{1}$ in the presence of $P$. demoleus cuticle. The secretion of protease in the presence of cuticle in the present investigation was lower compared to the results found by Murad et al. (2006, 2007), whose reports contained higher hydrolytic enzyme secretion in the presence and absence of Collasobruchus maculatus exoskeleton treated with Metarhizium anisopliae and Beauveria bassiana accordingly.

However the present investigation indicates relatively lower protein secretion by the $I f r_{1}$ in response to $P$. demoleus exoskeleton than $\mathrm{Ifr}_{2}$. The secretions were expected since the unique carbon and nitrogen sources supplied to the fungus were derived from chitin-rich and protein-rich exoskeletons. The proteinases and chitinase clearly indicates the strong support played by the secretomes in insect killing efficiency of the isolate $I \mathrm{fr}_{1}$ than $I f r_{2}$.

According to the basic structure of amino acids, and the presence of catalytic triad conserved amino acids, cuticle degrading proteases of the $I$. fumosorosea was confirmed with the report from FTIR and ${ }^{1} \mathrm{H}$ NMR. In the FTIR analysis, the presence $\mathrm{OH}, \mathrm{NH}_{2}, \mathrm{COOH}, \mathrm{CH}_{2}$ and $\mathrm{CH}$ groups of the catalytic triad amino acids (Serine, Histidine and Asparagine) were confirmed with peak positions. Presence of serine confirmed by obtaining the peak position at 3543,3405 and $1135\left(\mathrm{~cm}^{-1}\right)$ was shared by $\mathrm{OH}$ and $\mathrm{NH}_{2}$ group.

The peak position for Carboxyl $(\mathrm{COOH}), \mathrm{CH}_{2}$ and $\mathrm{CH}$ group were obtained at $2923\left(\mathrm{~cm}^{-1}\right)(\mathrm{OH}), 2932\left(\mathrm{~cm}^{-1}\right)$ (OH), 1708(C-O), $1702\left(\mathrm{~cm}^{-1}\right)(\mathrm{C}-\mathrm{O}), 1367\left(\mathrm{~cm}^{-1}\right)(\mathrm{O}-\mathrm{C})$, 2932 and $2932\left(\mathrm{~cm}^{-1}\right)$ accordingly. Besides, peak positions at $3459,1011,3405,2715,1216,1224$, and $2715\left(\mathrm{~cm}^{-1}\right)$ was shared by the histidine and asparagine amino acids. Thus, in the present study, not only presence of catalytic triad amino acids was confirmed but also the enzyme activity of the isolate comes under the serine protease criteria. Similarly, the presence of serine was also verified clearly in the ${ }^{1} \mathrm{H}$ NMR. The peak in the 
range 11-14 ppm confirmed the presence of $\mathrm{OH}$ group which was the main side chain of the amino acids serine besides, peak at $7.571 \mathrm{ppm}(\mathrm{CH}), 7.226,7.222$ and 6.873 ppm $(\mathrm{CH}), 4.893$ and $3.640 \mathrm{ppm}(\mathrm{CH}), 3.619$ and 3.597 ppm (CH2), 2.138 and 2.061 ppm $\left(\mathrm{NH}_{2}\right)$, represents the asparagine and its 2- Pyrrole imidazole ring $(7.571 \mathrm{ppm}$ $(\mathrm{CH})$ and $6.873 \mathrm{ppm}(\mathrm{CH})$. The peak at the $550,1.364$, $1.338,1.215,0.926,0.902$ and $0.878 \mathrm{ppm}$ has the histidine counterparts. Thus, the above information clearly confirm the presence of catalytic triad amino acids in the secreted proteome of $I$.fumosorosea towards $P$. demoleus exoskeleton.

\section{Conflict of Interests}

The author(s) have not declared any conflict of interest.

\section{REFERENCES}

Altre JA, Vandenberg JD, Cantone FA (1999). Pathogenicity of Paecilomyces fumosoroseus isolates to diamondback moth, Plutella xylostella: correlation with spore size, germination speed, and attachment to cuticle. J. Invertebr. Pathol.73:332- 338

Birktoft JJ, Blow DM (1972). Structure of alpha-chymotrypsin. J. Mol. Biol. 168:187-240.

Boucias DG, Pendland JC (1991). Attachment of mycopathogens to cuticle. In: Cole, G. T. and Hoch, H. C. (eds.): The fungal spore and disease initiation in plants and animals. Plenum Press, New York, London.

Charnley AK (1989). Mechanisms of fungal pathogenesis in insects. In Whipps JM \& Lumsden RD (Eds). The Biotechnology of fungi for improving plant growth. Cambridge University, London, pp. 85-125.

Charnley AK (1997). Entomopathogenic fungi and their role in pest control. In: Wicklow, D. T. and Söderström, B. E. (eds.): The Mycota IV, Environmental and Microbial Relationships. Springer Verlag, Berlin, Germany.

Clarkson J, Screen S, Bailey A, Cobb B, Charnley AK (1998). Fungal pathogenesis in insects. In: Bridge, $P$., Couteaudier, $Y$. and Clarkson, J. (eds.): Molecular variability of fungal pathogens. CAB International, Wallingford, UK.

Clarkson JM, Charnley AK (1996). New insights into the mechanisms of fungal pathogenesis in insects. Trends Microbiol. 4:197-203.

Dodson G, Wlodawer A (1998). Catalytic triads and their relatives. Trends Biochem. Sci. 23: 347-352.

Fang QX, Zhou YY, Hu YM, Yang SF, Gong YX (1985). Selection and cultivation of enhanced strains of Paecilomyces fumosoroseus to control Trialeurodes vaporariorum). Chin. J. Biol. Cont. 1(2):15-18 (in Chinese).

Fargues J, Rodriguez-Rueda D (1971). Sensibilité des oeufs des Noctuides Mamestra brassicae et Spodoptera littoralis aux Hyphomycetes Paecilomyces fumosoroseus et Nomuraea rileyi. C. R. Acad. Sci. 290(1):65-68.

Hajek AE, St. Leger RJ (1994). Interactions between fungal pathogens and insect hosts. Ann. Rev. Entomol. 39(1):293-322.

Haraprasad N, Niranjans SR, Prakash HS, Shetty HS Seema W (2001). Beauveria bassiana - A Potential Mycopesticide for the efficient control of coffee Berry Borer, Hypothenemus hampei (Ferrari) in India. Biocontrol Sci. Technol. 11:251-260.

Kaijiang L, Roberts DW (1986). The production of destruxins by the entomogenous fungus Metarhizium anisopliae var. major. J. Invertebr. Pathol. 47(1):120-122.

Lacey LA, Frutos R, Kaya HK Vail P (2001). Insect pathogens as biological control agents: Do they have a future? Biol. Control 21(3):230-248.
Liu SD, Lin SC, Shiau JF (1989). Microbial control of coconut leaf beetle (Brontispa longissima) with Green Muscardine fungus, Metarhizium anisopliae var. anisopliae. J. Invertebr. Pathol. 53(1):307-314.

Malsam O (1999). Optimierung der Wirksamkeit des entomopathogenen Pilzes Metarhizium anisopliae gegen Weife Fliegen. PhD thesis, Rhein. Friedrich-Wilhelms-Universitaet, Bonn, Germany.

Murad MA, Laumann RA, Mehta A, Noronha EF Franco OL (2007). Screening and secretomic analysis of enthomopatogenic Beauveria bassiana isolates in response to cowpea weevil (Callosobruchus maculatus) exoskeleton. Comp. Biochem. Physiol. 145:333-338.

Murad, MA, Laumann RA, Lima A, Sarmento RBC, Noronha EF, Rocha TL, Valadares-Inglis MC, Franco OL (2006). Screening of entomopathogenic Metarhizium anisopliae isolates and proteomic analysis of secretion synthesized in response to cowpea weevil (Callosobruchus maculatus) exoskeleton. Comp. Biochem. Physiol. C Toxicol. Pharmacol. 142:365-370.

Nugroho I, Ibrahim YB (2004). Laboratory Bioassay of Some Entomopathogenic Fungi against Broad Mite (Polyphagotarsonemus Latus Bank). Int. J. Agric. Biol. 6(2):223-225.

Rath AC, Guy PL, Webb WR (1996). Metarhizium spore surface antigens are correlated with pathogenicity. Mycol. Res. 100(1): 57-62.

Russell AJ, Fersht AR (1987). Rational modification of enzyme catalysis by engineering surface charge. Nature 328:496-500.

Schabel HG (1976). Oral infection of Hylobius pales by Metarhizium anisopliae. J. Invertebr. Pathol. 27(1):377-383.

Siezen RJ, Leunissen JAM (1997). Subtilases the superfamily of subtilisin- like serine proteases. Prot. Sci. 6:501-523.

St. Leger RJ, Cooper RM, Charnley AK (1986). Cuticle-degrading enzymes of entomopathogenic fungi: degradation in vitro by enzymes from entomopathogens. J. Invertebr. Pathol. 48:167-177.

St.Leger RJ, Butt TM, Goettel MS, Staples RC Roberts DW (1989). Production in vitro of appressoria by the entomopathogenic fungus Metarhizium anisopliae. Exp. Mycol. 13(3):274-288.

St.Leger RJ, Durrands PK, Charnley AK Cooper RM (1988). The role of extracellular chymoelastase in the virulence of Metarhizium anisopliae for Manduca sexta. J. Invertebr. Pathol. 52(1): 285-294.

St.Leger RJS, Charnley AK, Cooper RM (1987). Characterization of cuticle degrading protease produced by the entomopathogen Metarhizium anisopliae, Arch. Biochem. Biophys. 253:221-232.

Ulhoa CJ, Peberdy JF (1992). Purification and some properties of the extracellular chitinase produced by Tichoderma harizianum. Enzyme Microb. Technol. 14:236-240.

Van De Veire M, Degheele D, Van Lenteren JC (1996). Toxicity of the fungal pathogen Paecilomyces fumosoroseus, strain Apopka 97, to the greenhouse whitefly Trialeurodes vaporariorum and the parasitoid Encarsia formosa, and first results of a control experiment in glasshouse tomatoes. In: $I O B C$ wprs Bulletin, Proceedings of the meeting of the working group 'Integrated control in glasshouses', 20.25. May 1996, Vienna, Austria.

Vestergaard S, Gillespie AT, Butt TM, Schreiter G, Eilenberg J (1995). Pathogenicity of the hyphomycete fungi Verticillium lecanii and Metarhizium anisopliae to the western flower thrip s, Frankliniella occidentalis. Biocontrol. Sci. Technol. 5(2): 185-192.

Vey A, Fargues J (1977). Histological and ultrastructural studies of Beauveria bassiana infection in Leptinotarsa decemlineata larvae during ecdysis. J. Invertebr. Pathol. 30 (1):207-215.

Vey A, Fargues J, Robert PH (1982). Histological and ultrastructural studies of factors determining the specifity of pathotypes of the fungus Metarhizium anisopliae for Scarabeid larvae. Entomophaga 27(4):387-397.

Wraight SP, Carruthers RI, Bradley CA, Jaronski ST, Lacey LA, Wood P, Galaini-Wraight S (1998). Pathogenicity of the entomopathogenic fungi Paecilomyces spp. and Beauveria bassiana against the silverleaf whitefly, Bemisia argentifolii. J. Invertebr. Pathol. 71(1):217226 